\title{
Liquid chromatography-tandem mass spectrometry characterization of five new leucinostatins produced by Paecilomyces lilacinus $\mathbf{C G}-189$
}

\author{
Ana Flávia Canovas Martinez and Luiz Alberto Beraldo Moraes \\ The fungus Paecilomyces lilacinus produces leucinostatins-peptaibiotics that exert a range of biological activities including \\ antimalarial, antiviral, antitumor and phytotoxicity. In this paper, we developed an analytical method employing LC-MS/MS in \\ the precursor ion and product ion scan modes to elucidate five new leucinostatins. Direct Infusion (DI-MS) helped to identify \\ the most abundant leucinostatins: F, D B2, S, A and K. MS/MS analysis using a triple quadrupole operating at different scan \\ modes is a versatile tool to study natural products, especially peptaibiotics. Although DI-MS full-scan analysis is rapid and \\ sensitive, it cannot distinguish between peptide isomers. On the other hand, LC-MS/MS operated in the precursor ion and \\ product ion modes is time consuming, but allows identifying the structure of isomers or isobar in crude extracts. \\ The Journal of Antibiotics (2015) 68, 178-184; doi:10.1038/ja.2014.120; published online 3 September 2014
}

\section{INTRODUCTION}

Leucinostatins constitute a class of peptaibiotics comprising fungal secondary metabolites bearing non-protein $C \alpha$-monosubstituted $\alpha$-amino acid residues ( $\alpha$-aminoisobutyric acid or Aib). ${ }^{1}$ Peptaibiotics display interesting physicochemical and biological activities depending on particular structural properties, such as the formation of pores in bilayer lipid membranes. Antibacterial, antifungal, antiviral and antiparasitic activities; mitochondrial ATPase inhibition; immunosuppression; diminished platelet aggregation; and neuroleptic effects have been described for these compounds. ${ }^{2,3}$

Leucinostatins typically contain a linear sequence of nine $\alpha$-amino acid residues including the unusual amino acids cis-4-methyl-Lproline, hydroxyleucine and $\alpha$-Aib, ${ }^{4,5}$ as well as fatty acyl moieties consisting of seven carbon atoms at the $\mathrm{N}$ terminus (Table 1). Amphiphilic peptaibols show high preference for $\alpha$-helical conformations including 310 -helical motifs, in the presence of Aib residues, ${ }^{6}$ relating it to the biological activities found for leucinostatins. ${ }^{7,8}$

Nowadays, MS enables researchers to rapidly characterize compounds originated from microorganisms and plants using samples with low concentrations of the target analyte. Tandem MS coupled with separation techniques, especially LC (LC-MS/MS), is one of the most efficient analytical techniques to analyze natural products. ${ }^{9}$ LC-MS/MS has been employed to identify and characterize peptaibiotics. ${ }^{10,11}$ However, no method based on LC-MS/MS has been reported to characterize leucinostatins in particular.

In this context, this study aimed to develop a method based on LC-tandem MS (LC-ESI-MS/MS) to identify and characterize an array of leucinostatins originated from Paecilomyces lilacinus CG-189 during submerged fermentation. This investigation also weighed the advantages and disadvantages of applying the DI-MS and LC-MS techniques to analyze peptides from microbial crude extracts.

\section{RESULTS}

Leucinostatins identification

During our search for microorganisms as new producers of phytotoxic compounds, the ethyl acetate extract of Paecilomyces lilacinus isolated from soil exhibited high phytotoxic activity. DI-MS analysis in the positive full-scan mode revealed several peaks corresponding to peptaibiotic leucinostatins. The MS spectrum of the crude extract displayed the characteristic peak of the leucinostatin series (Figure 1). The ions at $m / z 1091,1105,1119,1135,1191,1205$ and 1219 were assigned to leucinostatins T, F, D, H, L, B or S, and A, respectively. The order of the amino acid sequence was determined by observation of a series of the fragment ions by LC-MS/MS (Support information, Supplementary Figures S1 and S2). Parent ion spectra from the CID experiments indicated amide bond cleavage, to yield $b$-type ions mainly. ${ }^{12}$ In addition, a value of $\Delta m / z=85 \mathrm{Da}$ for the fragment ions confirmed the presence of the marker amino acid Aib. To date, only one method has been described to identify a series of leucinostatins using an FAB ionization system. ${ }^{12}$

Figure 2a presents a positive full-scan LC-ESI-MS chromatogram of the peptaibiotics crude extract. The peaks observed in the range of 25-40 min corresponded to leucinostatins series. Three main peaks appeared at retention times (Rt) 29, 32 and $36 \mathrm{~min}$; they referred to

Laboratory of Mass Spectrometry Applied to Natural Products, Department of Chemistry, Faculty of Philosophy, Sciences and Letters of Ribeirão Preto, University of São Paulo (USP), Ribeirão Preto, Sao Paulo, Brazil

Correspondence: Professor LAB Moraes, Laboratory of Mass Spectrometry Applied to Natural Products, Department of Chemistry, Faculty of Philosophy, Sciences and Letters of Ribeirão Preto, University of São Paulo (USP), Ribeirão Preto, Sao Paulo 14040-901, Brazil

E-mail: luizmoraes@ffclrp.usp.br

Received 26 November 2013; revised 8 July 2014; accepted 23 July 2014; published online 3 September 2014 
Table 1 General structure and possible substituents found in leucinostatins

\begin{tabular}{|c|c|c|c|c|}
\hline & $\mathrm{R}_{2}$ & 0 & $\mathrm{~N}_{\mathrm{H}}$ & \\
\hline C & $-\mathrm{CH}_{3}$ & $-H$ & $-\mathrm{H},-\mathrm{H}$ & 1090 \\
\hline $\mathrm{T}$ & $-H$ & $-H$ & $-\mathrm{H},-\mathrm{CH}_{3}$ & 1090 \\
\hline $\mathrm{F}$ & $-\mathrm{CH}_{3}$ & $-\mathrm{H}$ & $-\mathrm{H},-\mathrm{CH}_{3}$ & 1104 \\
\hline D & $-\mathrm{CH}_{3}$ & $-H$ & $-\mathrm{CH}_{3},-\mathrm{CH}_{3}$ & 1118 \\
\hline N & $-\mathrm{CH}_{3}$ & $-\mathrm{OH}$ & $-\mathrm{H},-\mathrm{CH}_{3}$ & 1120 \\
\hline A2 & $-\mathrm{CH}_{3}$ & $\mathrm{CH}_{3} \mathrm{CH}_{2} \mathrm{COCH}=\mathrm{CH}-$ & $-\mathrm{CH}_{3},-\mathrm{CH}_{3}$ & 1200 \\
\hline $\mathrm{R}$ & $-\mathrm{CH}_{3}$ & $\mathrm{CH}_{3} \mathrm{CH}_{2} \mathrm{COCH}_{2} \mathrm{CH}_{2-}$ & $-\mathrm{CH}_{3},-\mathrm{CH}_{3}$ & 1202 \\
\hline B & $-\mathrm{CH}_{3}$ & $\mathrm{CH}_{3} \mathrm{CH}_{2} \mathrm{COCH}_{2}(\mathrm{OH}) \mathrm{CH}-$ & $-\mathrm{H},-\mathrm{CH}_{3}$ & 1204 \\
\hline S & $-\mathrm{CH}_{3}$ & $\mathrm{CH}_{3} \mathrm{CH}_{2} \mathrm{CH}(\mathrm{OH}) \mathrm{CH}_{2} \mathrm{CH}_{2-}$ & $-\mathrm{CH}_{3},-\mathrm{CH}_{3}$ & 1204 \\
\hline A & $-\mathrm{CH}_{3}$ & $\mathrm{CH}_{3} \mathrm{CH}_{2} \mathrm{COCH}_{2}(\mathrm{OH}) \mathrm{CH}-$ & $-\mathrm{CH}_{3},-\mathrm{CH}_{3}$ & 1218 \\
\hline U & $-\mathrm{CH}_{3}$ & $\mathrm{CH}_{3} \mathrm{CH}_{2} \mathrm{COCH}_{2}\left(\mathrm{OCH}_{3}\right) \mathrm{CH}$ & $-\mathrm{H},-\mathrm{CH}_{3}$ & 1218 \\
\hline K & $-\mathrm{CH}_{3}$ & $\mathrm{CH}_{3} \mathrm{CH}_{2} \mathrm{COCH}_{2}(\mathrm{OH}) \mathrm{CH}-$ & $-\mathrm{CH}_{3},-\mathrm{CH}_{3},(\mathrm{O})$ & 1234 \\
\hline W & $-\mathrm{CH}_{3}$ & $\left(\mathrm{C}_{10} \mathrm{H}_{15} \mathrm{O}_{3}\right)_{-}$ & $-\mathrm{H},-\mathrm{CH}_{3}$ & 1286 \\
\hline Q & $-\mathrm{CH}_{3}$ & $\left(\mathrm{C}_{11} \mathrm{H}_{17} \mathrm{O}_{3}\right)-$ & $-\mathrm{H},-\mathrm{CH}_{3}$ & 1300 \\
\hline 0 & $-\mathrm{CH}_{3}$ & $\left(\mathrm{C}_{11} \mathrm{H}_{17} \mathrm{O}_{3}\right)-$ & $-\mathrm{CH}_{3},-\mathrm{CH}_{3}$ & 1314 \\
\hline \multicolumn{5}{|c|}{ New identified leucinostatins } \\
\hline 1 & $-H$ & $-\mathrm{CH}_{3}$ & $-\mathrm{CH}_{3},-\mathrm{CH}_{3}$ & 1104 \\
\hline
\end{tabular}

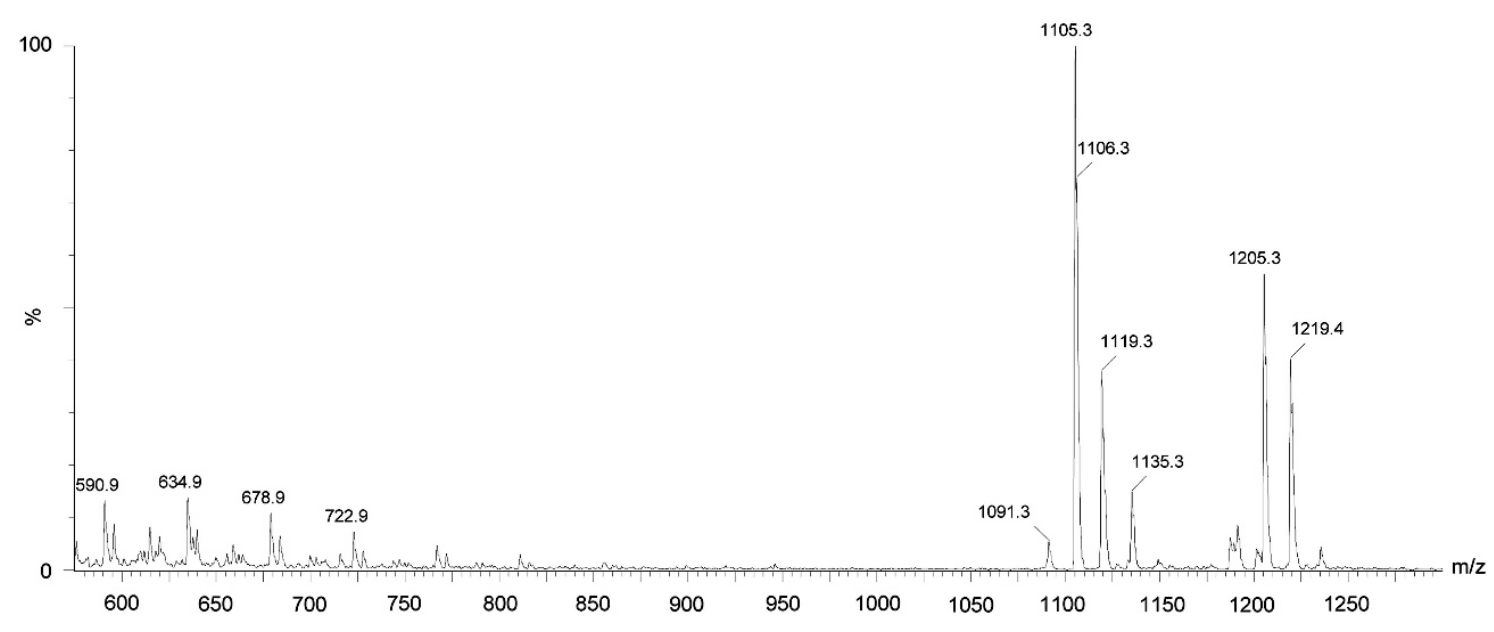

Figure 1 DI-MS $(\mathrm{ESI}+)$ of the crude extract.

the protonated molecules $[\mathrm{M}+\mathrm{H}]^{+} \mathrm{m} / z 1205$ (Leu B), 1219 (Leu A) and 1119 (Leu D) in the positive mode. However, leucinostatins have different isoform structures, produced by nonribosomal peptide synthetases. The extracted ion current (EIC) for the ions at $\mathrm{m} / \mathrm{z}$
$1105,1121,1191$ and 1205 (Figures 2b-e) that were present in the crude extract exhibited more peaks than expected.

For example, the EIC chromatogram of the ion at $\mathrm{m} / z 1105$ (Figure 2b) displayed two peaks, at Rt 33 and $35 \mathrm{~min}$, whereas only 

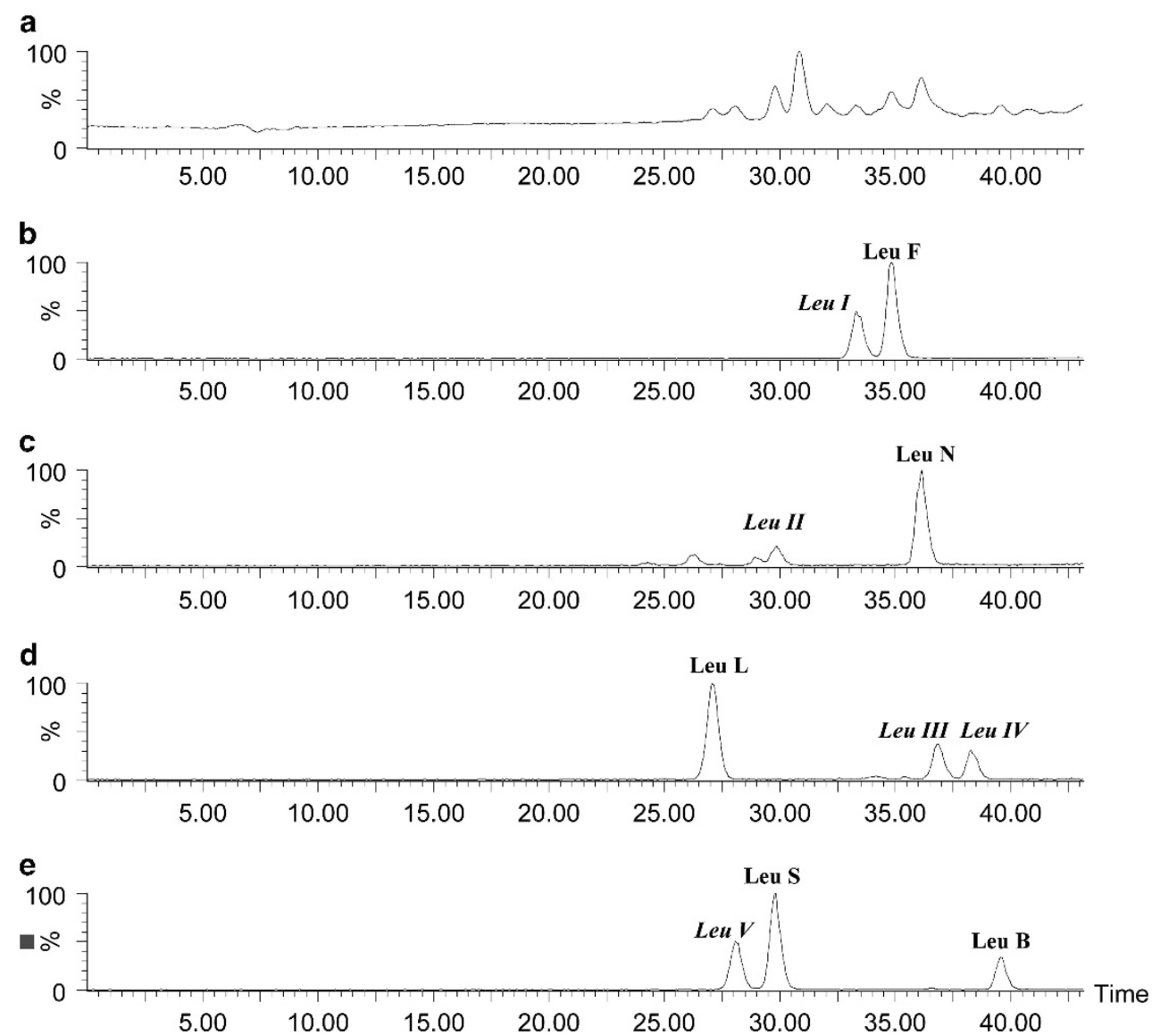

Figure 2 (a) LC-MS full scan of the crude extract in the positive mode and extracted ion chromatograms of the ions (b) $\mathrm{m} / \mathrm{z} 1105,(\mathbf{c}) \mathrm{m} / \mathrm{z} 1121$, (d) $\mathrm{m} / \mathrm{z}$ 1191 and (e) $m / z 1205$.
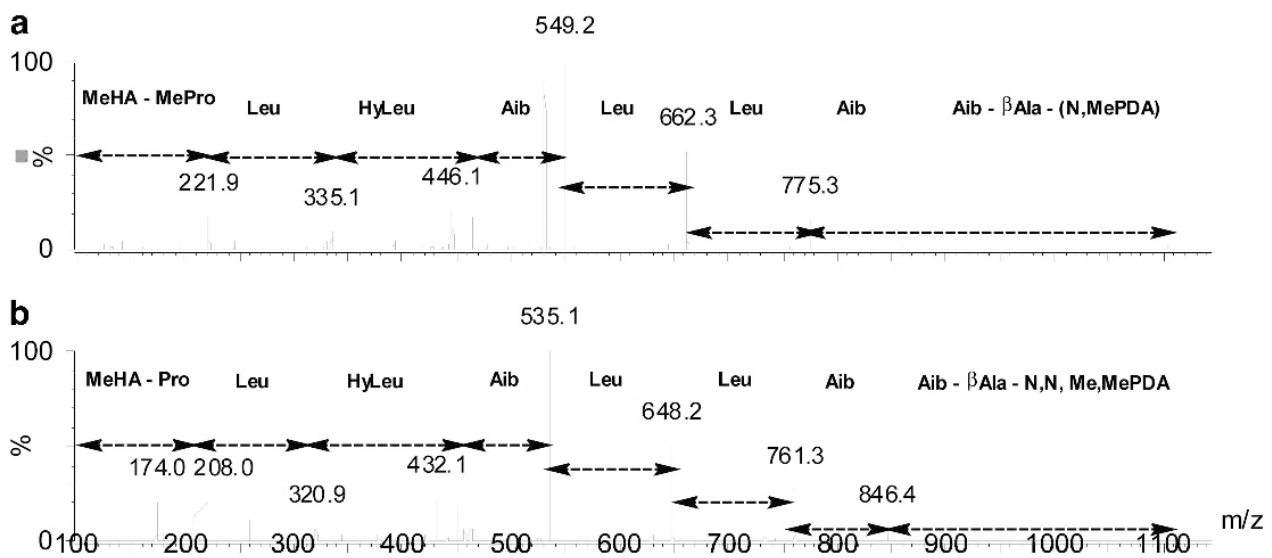

Figure $3 \mathrm{CID}$ spectra for the ions at $\mathrm{m} / \mathrm{z} 1105$ to (a) leucinostatin $\mathrm{F}$ and (b) leucinostatin I. A full color version of this figure is available at The Journal of Antibiotics journal online.

leucinostatin $\mathrm{F}$ has been reported to have this MW (Table 1). As for the EIC chromatogram of the ion at $m / z 1191$ (Figure 2d), it afforded three peaks, at Rt 27, 37 and $38 \mathrm{~min}$, whereas only one peak was expected. Likewise, the EIC chromatogram of the ion at $\mathrm{m} / z 1205$ (Figure 2e) contained three signals, whereas two were expected. These results suggested that the crude extract produced by Paecilomyces lilacinus CG-189 contained a lot of new leucinostatin isoforms.

Although DI-MS analyses are fast (about $0.5 \mathrm{~min}$ per sample), this type of experiment does not distinguish between isomers. DI-MS is more useful in screening studies to determine chemical profiles. To evaluate samples containing isomers, LC-MS experiments are more suitable, despite the long analysis time required.

\section{Leucinostatin characterization}

Table 1 shows that only hydrogen or a methyl group can occupy position $\mathrm{R}_{1}$ in leucinostatins. All the described leucinostatins displayed one of these substituents, and the lipid portion was the same in all of them. ${ }^{13}$ When $\mathrm{R}_{1}=-\mathrm{H}$ or $-\mathrm{CH}_{3}$, the product ions observed in 

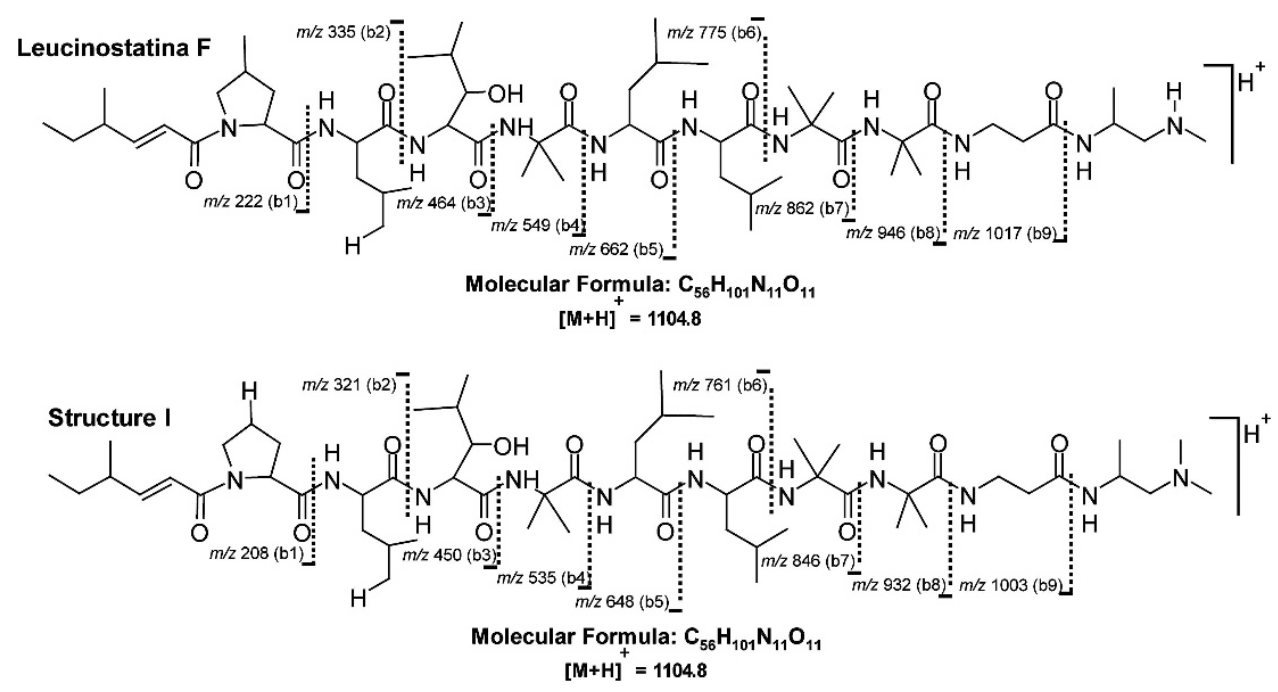

Figure 4 Structures of leucinostatin $\mathrm{F}$ and the new leucinostatin $I$.

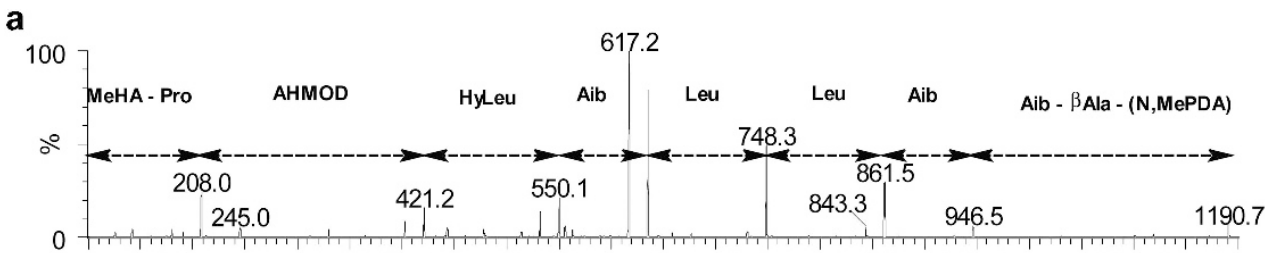

b
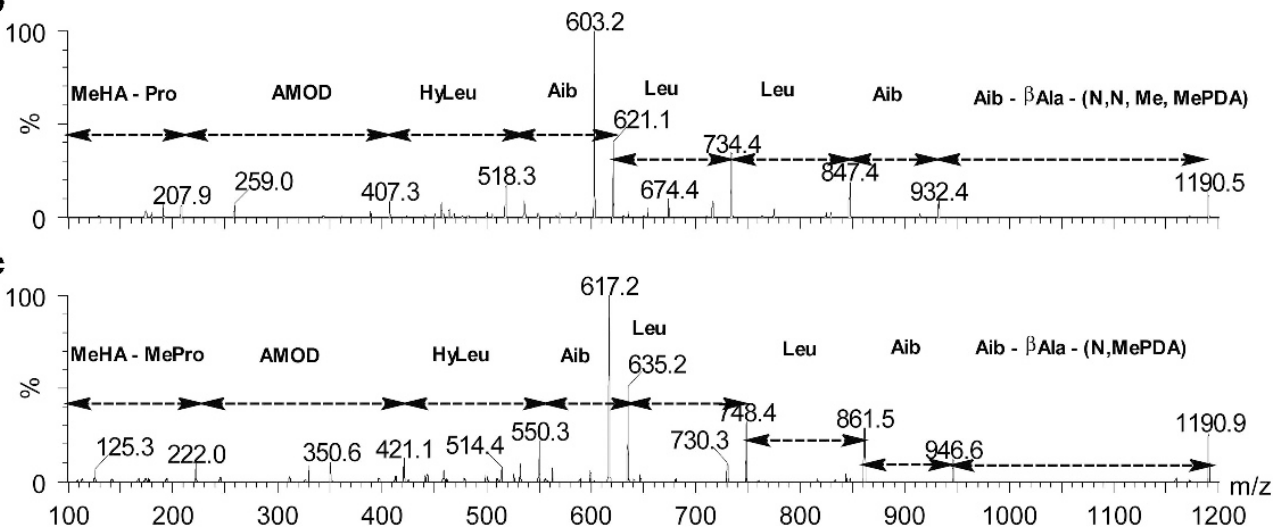

Figure $5 \mathrm{CID}$ spectra for the ions at $\mathrm{m} / \mathrm{z} 1191$ at (a) leucinostatin L, (b) leucinostatin III and (c) leucinostatin IV.

CID experiments were $m / z 208$ or 222 , respectively. These product ions helped to determinate new isoforms of leucinostatins.

In the chromatogram in Figure $2 b$, the peak $35 \mathrm{~min}(\mathrm{~m} / \mathrm{z} 1105)$ referred to leucinostatin $\mathrm{F}$. The product ion spectrum of the protonated leucinostatin $\mathrm{F}$ ion of $\mathrm{m} / \mathrm{z} 1105$ gave ions at $\mathrm{m} / \mathrm{z} 860$, $775,662,549,464,446,335$ and 222 (Figure 3a). For the new leucinostatin $(\mathrm{m} / \mathrm{z} 1105)$ at Rt $33 \mathrm{~min}$, the product ions had $\mathrm{m} / \mathrm{z} 846$, $761,648,535,450,432,321$ and 208 (Figure $3 b$ ). Other signals typical of the fragments of these structures were $\mathrm{m} / \mathrm{z} 860$ (Leu F), indicating loss of Aib-BAla-(N,MePDA), and $m / z 846$ (Leu $I$ ), showing loss of Aib- $\beta$ Ala-(N,N,Me,MePDA). The new leucinostatin ion at $m / z 1105$ was assigned the leucinostatin $I$ (Figure 4).

Figure 4 shows that leucinostatin $I$ contains the substituent $-\mathrm{CH}_{3}$ in position $\mathrm{R}_{4}$, whereas leucinostatin $\mathrm{F}$ bears $-\mathrm{H}$ at this position. Leucinostatins $\mathrm{F}$ and $\mathrm{I}$ show differences in the positions $\mathrm{R}_{1}$ and $\mathrm{R}_{4}$ (Figure 4). While the leucinostatin $I$ contains the substituent $-\mathrm{CH}_{3}$ in position $\mathrm{R}_{4}$, the leucinostatin $\mathrm{F}$ bears $-\mathrm{H}$ at this position. Another difference exists at position $\mathrm{R}_{1}$ which are observed the substituents are $-\mathrm{H}$ and $-\mathrm{CH}_{3}$ in leucinostatins $I$ and $\mathrm{F}$, respectively. Therefore, leucinostatins $I$ and F are isomers and thus DI-MS cannot distinguish between them.

For the ion at $m / z 1191$, only one chromatographic peak was expected referring to leucinostatin L (Table 1), which arose at Rt $27 \mathrm{~min}$ (Figure 2d). On the basis of its fragmentation sequence (see Figure 5) $\mathrm{m} / \mathrm{z}$ 946, 861, 748, 635, 550, 421 and 208, the ion fragments at $m / z 946,421$ and 208 were attributed to $\mathrm{R}_{4}=-\mathrm{CH}_{3}, \mathrm{R}_{3}=-\mathrm{H}$, $\mathrm{R}_{2}=\mathrm{CH}_{3} \mathrm{CH}_{2} \mathrm{COCH}_{2}(\mathrm{OH}) \mathrm{CH}$ - and $\mathrm{R}_{1}=-\mathrm{H}$. However, two new unexpected peaks emerged at Rt 37 and $38 \mathrm{~min}$, with fragmentation sequence at $m / z$ 932, 847, 734, 621, 603, 536, 407 and 208, and $m / z$ $946,861,748,635,550,421$ and 222 , respectively.

The fragmentation pattern of the three compounds at $\mathrm{m} / \mathrm{z} 1191$ us to assign the structure of the two new leucinostatins at $\mathrm{m} / \mathrm{z} 1191$. The 

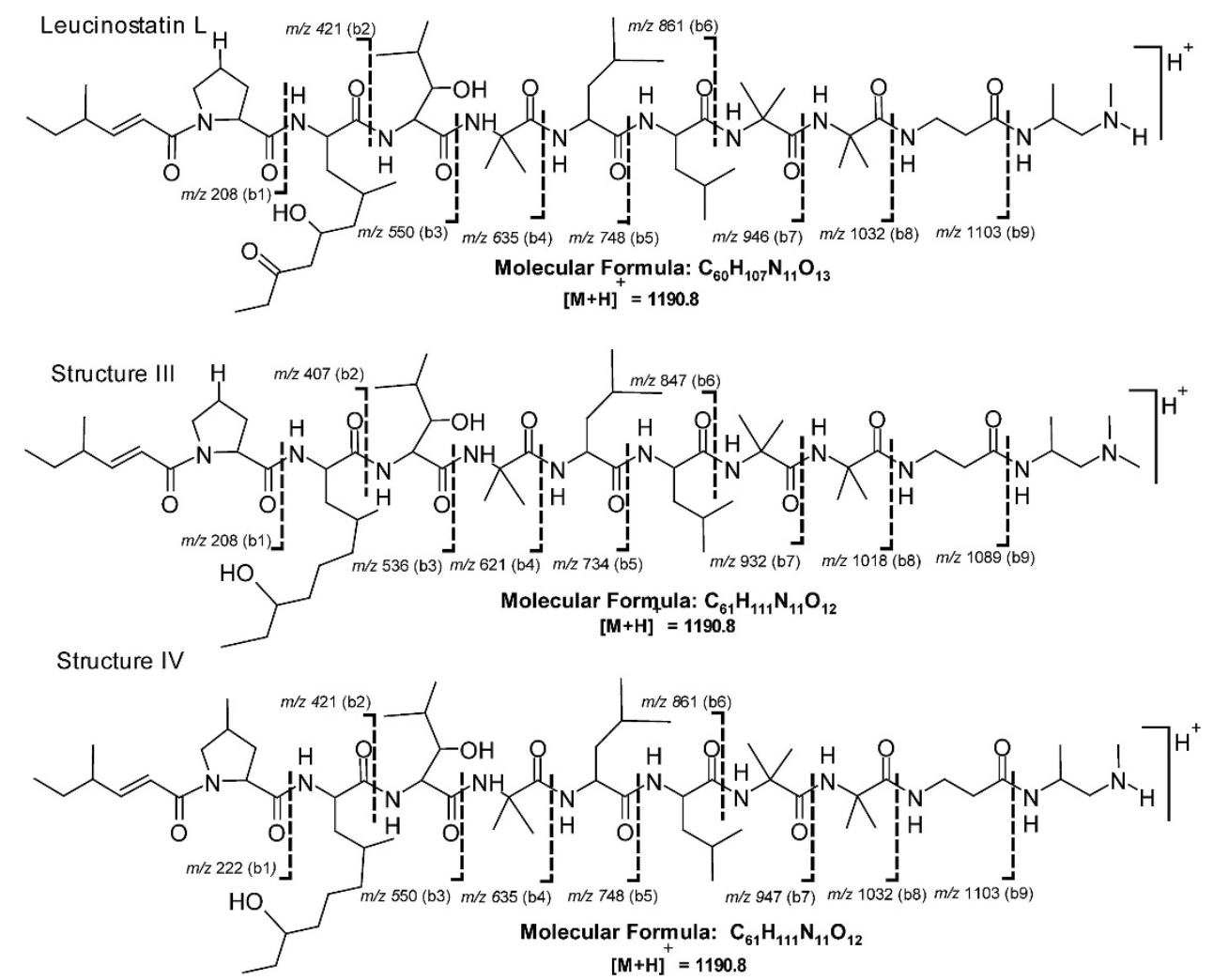

Figure 6 Structures for leucinostatins L, III and IV.
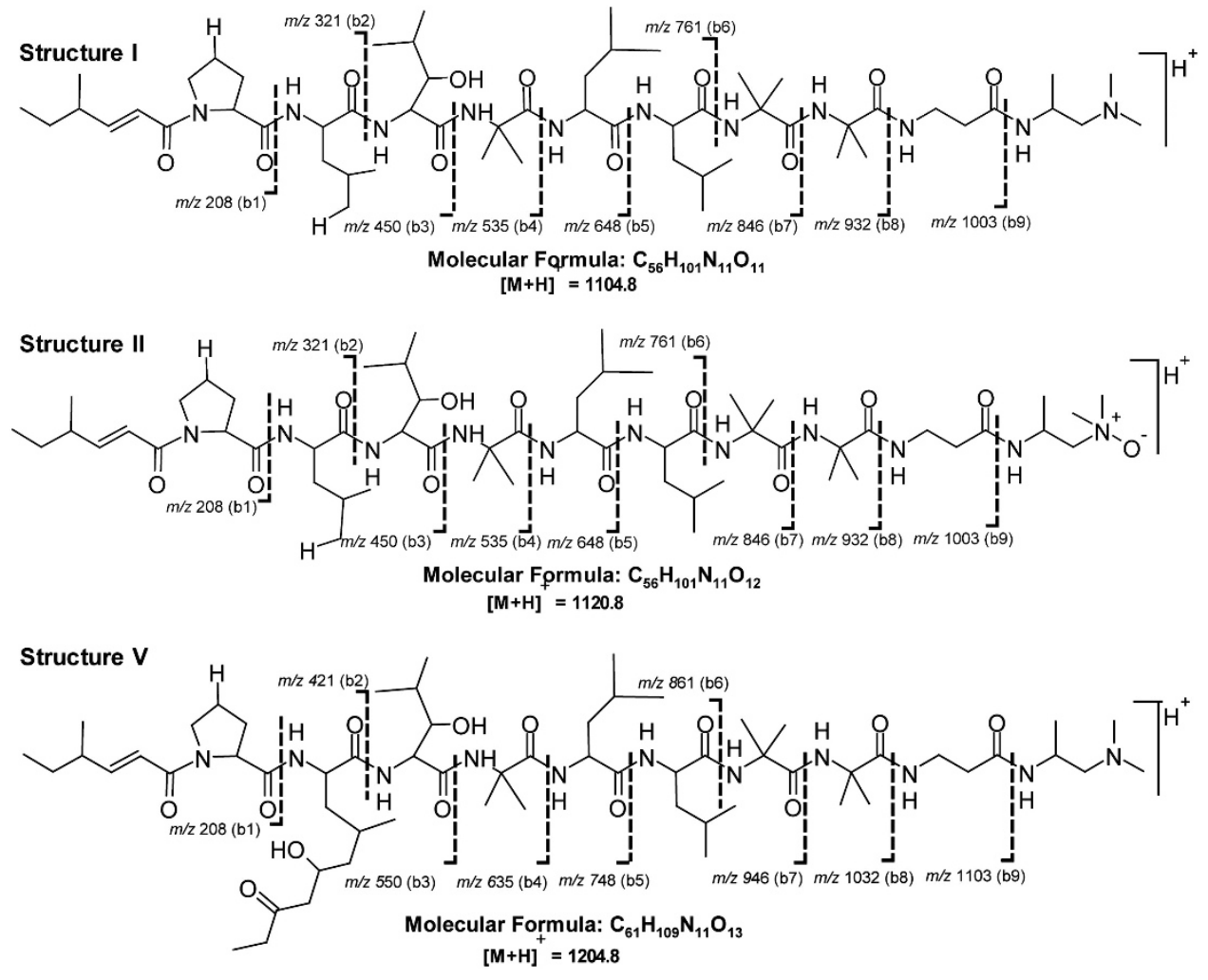

Figure 7 Structures of the new leucinostatins I, II and V. 

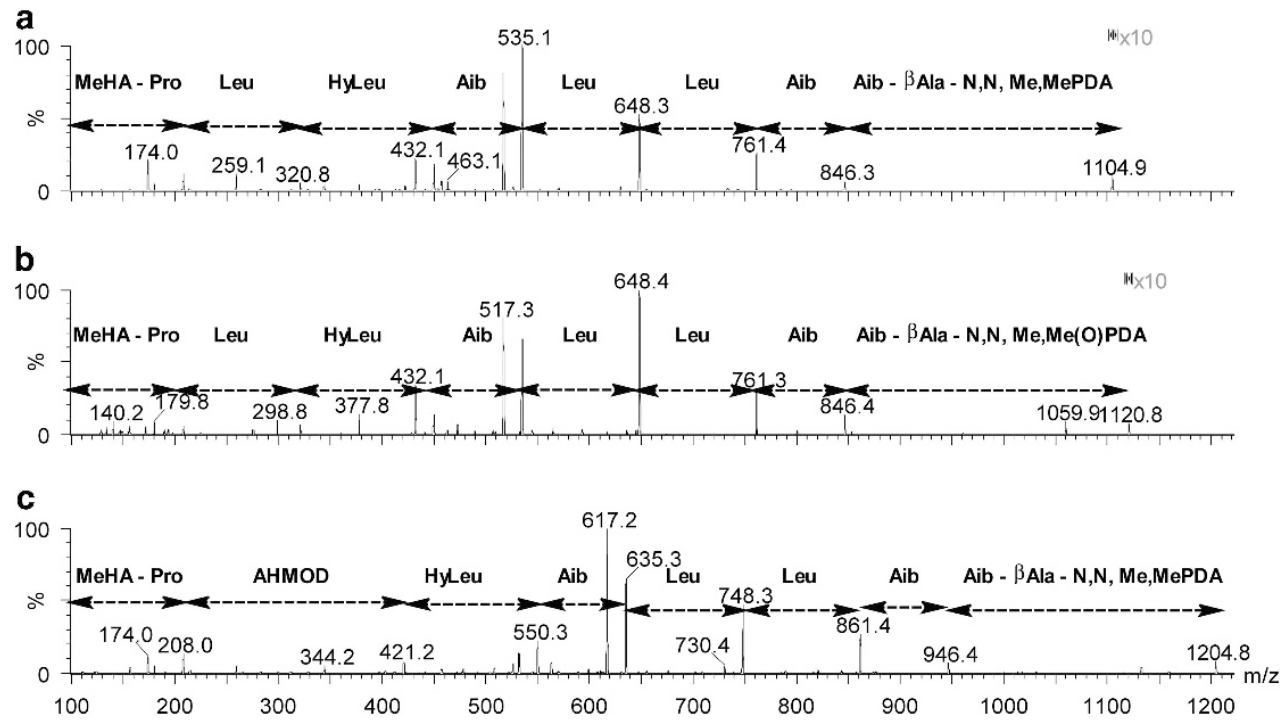

Figure $8 \mathrm{CID}$ spectra of the new leucinostatins (a) I, (b) II and (c) V. A full color version of this figure is available at The Journal of Antibiotics journal online.

fragments at $m / z 208$ and 222 indicated different substituents (-H and $-\mathrm{CH}_{3}$ ) in $\mathrm{R}_{1}$, while the ions $m / z 932$ and 947 suggested loss of Aib$\beta A l a-(N, M e P D A)$ and Aib- $\beta A l a-(N, N, M e, M e P D A)$, respectively.

The peak at Rt $37 \mathrm{~min}$ afforded fragment ions at $\mathrm{m} / \mathrm{z}$ 932, 407 and 208, ascribed to $\mathrm{R}_{4}=\mathrm{R}_{3}=-\mathrm{CH}_{3}, \mathrm{R}_{2}=\mathrm{CH}_{3} \mathrm{CH}_{2} \mathrm{CH}(\mathrm{OH}) \mathrm{CH}_{2} \mathrm{CH}_{2^{-}}$, and $\mathrm{R}_{1}=-\mathrm{H}$, respectively. The peak with $\mathrm{Rt} 38 \mathrm{~min}$ furnished fragment ions at $m / z 947,421$ and 222, assigned to $\mathrm{R}_{4}=\mathrm{R}_{1}=-\mathrm{CH}_{3}$, $\mathrm{R}_{3}=-\mathrm{H}$, and $\mathrm{R}_{2}=\mathrm{CH}_{3} \mathrm{CH}_{2} \mathrm{CH}(\mathrm{OH}) \mathrm{CH}_{2} \mathrm{CH}_{2}$, respectively. This is the first description of compounds with Rt 37 and 38 min that were designated as leucinostatins $I I I$ and $I V$, respectively (Figure 6).

The same strategy was used to characterize the ion at $\mathrm{m} / \mathrm{z} 1205$. The EIC chromatogram peak at Rt 26 min (Figure 2e) afforded product ions at $\mathrm{m} / \mathrm{z}$ 946, 861, 748, 635, 550, 421 and 208. The fragmentation sequence of these product ions had a mass difference $\Delta m / z$ of $100 \mathrm{Da}$ relative to leucinostatin $I$; its mass difference suggested the presence of the group AHMOD in $\mathrm{R}_{2}$ (Figure 7, structure V). The peaks at Rt 30 and 39 min were attributed to known leucinostatin $S$ and $B$, based on fragmentation sequence.

The LC-MS/MS experiment employing the product ion at $\mathrm{m} / \mathrm{z}$ 1121 and Rt 29 min (Figure 2b) gave fragmentation sequence ions at $m / z$ 846, 762, 648, 535, 450 and 208 (Figure 8, leucinostatin $I I$ ). The product ions at $m / z 846$ corresponded to loss of Aib-BAla-N,N$\mathrm{Me}, \mathrm{Me}(\mathrm{O}) \mathrm{PDA}$ from the parent ion at $\mathrm{m} / \mathrm{z} 1121$ (see Figure $7 \mathrm{~b}$ ).

\section{DISCUSSION}

\section{Leucinostatin characterization in the crude extract}

The DI-MS spectra allowed us to identify ions in series that corresponded to compounds belonging to the class of leucinostatins. However, only LC-MS/MS analyses were able to structurally identify and characterize isomers.

\section{Parent ion experiments}

LC-MS/MS experiments were extremely important: they confirmed the proposed new structures. At first, putting the new structures forward resembled a puzzle-it was necessary to join structural fragments and to propose the structures of the new isolated compounds. These experiments required only a low amount of the sample to obtain of structural information.
In conclusion, this work presented a versatile dereplication method consisting of DI-MS, LC-ESI-MS and LC-ESI-MS/MS analyses to characterize peptaibiotic leucinostatins in crude microbial extracts. It was possible to identify five new leucinostatins in the ethyl acetate crude extracts of the fungal strain Paecilomyces lilacinus CG 189. First, DI-MS studies provided the profiles of ions pattern of the leucinostatin families. Then, based on CID experiments (LC-ESI-MS/ MS), five new leucinostatins were characterized. These experiments shall accelerate the discovery of new compounds, aiding studies of natural products. This technique is useful because the low amount of crude extracts is obtained in fermentation process, which calls for sensitive techniques to structurally elucidate novel compounds.

New leucinostatins characterized in this study were not submitted to phytotoxic activity assay.

\section{MATERIALS AND METHODS}

\section{Solvents}

Acetonitrile $(\mathrm{ACN})$ and methanol $(\mathrm{MeOH})$ were purchased from J.T. Baker (Mallinckrodt Pharmaceuticals, Dublin, Ireland); ethyl acetate was acquired from Synth (São Paulo, Brasil) and trifluoroacetic acid was obtained from Sigma-Aldrich (St Louis, MO, USA).

\section{Fungal culture and fermentation conditions}

Leucinostatins were produced by the fungus Paecilomyces lilacinus CG 189 isolated from the soil in the city of Formosa, state of Goiás, Brazil. The microorganism was maintained in PDA medium plates (Acumedia, Neogen do Brasil, Indaiatuba, Brasil).

Paecilomyces lilacinus was inoculated in a medium containing salts ${ }^{13}$ (2\% glucose, $2.5 \mathrm{~g}$ of $\mathrm{NaNO}_{3}, 0.0015 \mathrm{~g}$ of $\mathrm{ZnSO}_{4} \cdot 7 \mathrm{H}_{2} \mathrm{O}, 0.0005 \mathrm{~g}$ of $\mathrm{FeSO}_{4} \cdot 7 \mathrm{H}_{2} \mathrm{O}, 0.0015 \mathrm{~g}$ of $\mathrm{MnSO}_{4} \cdot \mathrm{H}_{2} \mathrm{O}, 0.0003 \mathrm{~g}$ of $\mathrm{H}_{3} \mathrm{BO}_{3}, 0.00015 \mathrm{~g}$ of $\mathrm{CuSO}_{4} \cdot 5 \mathrm{H}_{2} \mathrm{O}, 0.0001 \mathrm{~g}$ of $\mathrm{Na}_{2} \mathrm{MoO}_{4} \cdot 2 \mathrm{H}_{2} \mathrm{O}, 0.05 \mathrm{~g}$ of $\mathrm{CaCl}_{2} \cdot 2 \mathrm{H}_{2} \mathrm{O}, 0.4 \mathrm{~g}$ of $\mathrm{MgSO}_{4} \cdot 7 \mathrm{H}_{2} \mathrm{O}, 1 \mathrm{~g}$ of $\mathrm{NaCl}, 1 \mathrm{~g}$ of $\mathrm{KCl}, 10 \mathrm{ml}$ of $\mathrm{H}_{3} \mathrm{PO}_{4}(85 \%), 11$ of distilled water). For $\mathrm{pH}$ adjustment, $\mathrm{KOH}$ pellets were used $(\mathrm{pH} 6)$. The fermentation was maintained for 10 days, at room temperature, in static conditions. The crude extract was obtained by consecutive liquid-liquid extractions with ethyl acetate ((1:1) ethyl acetate/fermentation volume).

\section{LC-MS analysis}

All the crude extract analyses were performed by online HPLC-MS on a Xevo TQ-S (Waters Corporation, Milford, MA, USA) mass spectrometer. The HPLC 
component consisted of an Acquity Ultra High Performance Liquid Chromatography system (UPLC-Waters) equipped with an auto sampler and a Luna C18(2) $(100 \times 4.60 \mathrm{~mm}, 5 \mu \mathrm{m}$, Phenomenex, Torrance, CA, USA). The mass spectrometer operated with ESI in the positive mode $(\mathrm{ESI}+)$, in the scan range $m / z \quad 100-1250$ and $m / z 550-1300$ for MS/MS and LC/MS, respectively. The solvents employed in the elution were: mobile phase A $(0.1 \%$ trifluoroacetic acid) and mobile phase B (acetonitrile). Run started with $40 \%$ phase B and increased linearly to $98 \%$ within $40 \mathrm{~min}$, maintaining this proportion by $10 \mathrm{~min}\left(98 \%\right.$ phase B). The flow rate was $0.150 \mathrm{ml} \mathrm{min}^{-1}$. The capillary voltage and the spray voltage were set to $3.3 \mathrm{kV}$ and $70 \mathrm{~V}$, respectively; the desolvation temperature was $350^{\circ} \mathrm{C}$; and the collision gas argon. For the LC-MS/MS experiments, the concentration of the crude extracts was $5 \mu \mathrm{g} \mathrm{ml}^{-1}$ in $\mathrm{MeOH}$.

\section{ACKNOWLEDGEMENTS}

We wish to acknowledge Fundação de Amparo à Pesquisa do Estado de São Paulo (FAPESP Processo 2009/54094-0) and Conselho Nacional de Desenvolvimento Científico e Tecnológico $(\mathrm{CNPq})$ for financial support. Researchers Myrian Tigano and Maria Regina Carneiro (Cenargen-Embrapa) are acknowledged for providing the fungal strains. Dr Cynthia Manso is acknowledged for revising and editing the manuscript.

1 Degenkolb, T. \& Bruckner, H. Peptaibiomics: towards a myriad of bioactive peptides containing $c \alpha$-dialkylamino acids? Chem. Biodivers. 5, 1817-1843 (2008).

2 Degenkolb, T., Kirschbaum, J. \& Bruckner, H. New sequences, constituents, and producers of peptaibiotics: an updated review. Chem. Biodivers. 4, 1052-1067 (2007).
3 Degenkolb, T., Berg, A., Gams, W., Schlegel, B. \& Grafe, U. The occurrence of peptaibols and structurally related peptaibiotics in fungi and their mass spectrometric identification via diagnostic fragment ions. Pept. Sci. 9, 666-678 (2003).

4 Abraham, R. J., McLauchlan, K. A., Dalby, S., Kenner, G. W. \& Sheppard, R. C. Structures and conformations of some naturally occurring of proline. Nature 192, 1150-1153 (1961)

5 Kenner, G. W. \& Sheppard, R. C. Alpha-Aminoisobutyric acid, beta-hydroxyleucine, and gamma-methylproline from the hydrolysis of a natural product. Nature $181,48-49$ (1958).

6 Toniolo, C. \& Benedetti, E. The polypeptide 310-helix. Trends Biochem. Sci. 16, 350-352 (1991).

7 Mori, Y., Tsuboi, M., Suzuki, M., Fukushima, K. \& Arai, T. Structure of leucinostatin A new peptide antibiotic from Paecilomyces lilacinus A-267. J. Chem. Soc. 94-96 (1982).

8 Ishiguro, K. \& Arai, T. Action of the peptide antibiotic leucinostatin. Antimicrob. Agents Chemother. 9, 893-898 (1976).

9 Nielsen, K. F., Mansson, M., Rank, C., Frisvad, J. C. \& Larsen, T. O. Dereplication of microbial natural products by LC-DAD-TOFMS. J. Nat. Prod. 74, 2338-2348 (2011).

10 Kimonyo, A. \& Bruckner, H. Sequences of metanicins, 20-residue peptaibols from the ascomycetous fungus CBS 597.80. Chem. Biodivers. 10, 813-826 (2013).

11 Jaworski, A. \& Bruckner, H. New sequences and new fungal producers of peptaibol antibiotics antiamoebins. J. Peptide Sci. 6, 149-167 (2000).

12 Isogai, A., Nakayama, J., Takayama, S., Kusai, A. \& Suzuki, A. Structural elucidation of minor components of peptidyl antibiotic P168s (leucinostatins) by tandem mass spectrometry. Biosci. Biotechnol. Biochem. 56, 1079-1085 (1992).

13 Tian, Q., Giusti, M. M., Stoner, G. D. \& Schwartz, S. J. Screening for anthocyanins using high-performance liquid chromatography coupled to electrospray ionization tandem mass spectrometry with precursor-ion analysis, product-ion analysis, common-neutral-loss analysis, and selected reaction monitoring. J. Chromatogr. A $1091,72-82$ (2005)

Supplementary Information accompanies the paper on The Journal of Antibiotics website (http://www.nature.com/ja) 